\title{
SNOW COVER DISTRIBUTION'S CORRELATION WITH CLIMATIC FACTORS IN NORTHEAST CHINA'S MOLLISOL REGION
}

\author{
SHI, H. - ZHOU, L. L. - XU, X. Q. - FAN, H. M. * \\ Shenyang Agricultural University, No. 120 Dongling Road, Shenyang, Liaoning, China \\ (phone: +86-186-4010-6289) \\ *Corresponding author \\ e-mail: fanhaoming@syau.edu.cn \\ (Received 22 ${ }^{\text {nd }}$ Apr 2020; accepted $13^{\text {th }}$ Aug 2020)
}

\begin{abstract}
Snow cover greatly influences climate in Northeast China, and it is one of the most relevant parameters to analyze climate change. The Mollisol area of Northeast China is one of the three seasonal snow areas in the country. This study investigates the spatial distribution characteristics and variation trends of monthly snow depth over a 30-year period. Linear regression analysis was applied for each factor. The results indicated a non-significant decreasing trend of snow depth in the mountainous area. Snow depth in the plains increased by $0-0.4 \mathrm{~cm} /$ year. The spatial distribution of first, last, and cover days of snow, and the maximum depth of snow cover were consistent in their correlation with snow cover depth. The snow cover gradually decreased with increasing temperature, latitude, and change in topography (altitude) from northeast to southwest. In terms of snow cover days, the highest correlation was obtained for temperature during the snow accumulation and melting periods. In contrast, there was no correlation with precipitation. The volume of snowmelt water had a significant change every 10 years. Keywords: snow depth, snow cover days, climate change, snowmelt water volume, spatiotemporal distribution
\end{abstract}

\section{Introduction}

Accumulated snow is an important source of freshwater in the Mollisol area of northeast China, where its average depth is $2-20 \mathrm{~cm}$. Snowmelt provides water for industrial, agricultural, and domestic supplies in spring. Owing to approximately 100 years of intensive and uncontrolled development, utilization of water resources and soil erosion in this area are intensive. The combined effects of snowmelt runoff, freezing-thawing cycles, and incomplete thawed layer cause slope erosion and rill formation. With higher number of confluences, rills develop into ephemeral and young gullies (Xu et al., 2019). Therefore, it is important to analyze the spatiotemporal variation of snow depth in the Mollisol area of northeast China.

In recent decades, remote sensing has been effectively utilized to monitor snow dynamics at regional and global scales (Li et al., 2018). In April 1960, the Television Infrared Observation Satellite TIROS-1 was used to monitor snow cover in Canada for the first time. The optical sensor was mainly used for monitoring snow areas and albedos, but that was restricted by weather conditions. Quantitative remote sensing was then applied to solve the issue of cloud cover and achieve better accuracy of remotely sensed data (Basang et al., 2017; Chang et al., 2017). In recent years, passive microwave remote sensing with features of all-weather, multi-polarization, and limited penetration of the underlying surface of the earth has been widely used for snow monitoring. When compared with optical sensor satellites, microwave remote sensing satellites are more accurate and timelier in the acquisition of snow depth, snow-water 
equivalent, and snow cover. A common passive microwave sensor satellite includes a Scanning Multichannel Microwave Radiometer (SMMR), the Defense Meteorological Satellite Program (DMSP), and a series of special microwave imaging detectors such as the Special Sensor Microwave Imager (SSM/I) and Advanced Microwave Scanning Radiometer-EOS (AMSR-E) (Josberger et al., 2017; Tang et al., 2019).

Snow covers present high albedo and thermal insulation, and they are important for the global climate system and hydrological cycles (Brown et al., 2007; Li et al., 2019; Zhang, 2005). Snow affects the relationship between ground systems and climate, thereby influencing climate change (Scipión et al., 2013; Fassnacht et al., 2018; Tan et al., 2019). The accumulation of snow in arid and semiarid areas provides water for the ecosystem and human society. Snow depth is an easy parameter to measure and an important characteristic of snow cover (Liu et al., 2018), and it can be used to derive snow-water equivalent. In this calculation, the spatial variation of snow density is less significant than snow depth (Fassnacht et al., 2013; López-Moreno et al., 2013). Area and duration of snow cover and snow-water equivalent have decreased because of global warming (Kunkel et al., 2016). Foster et al. (1997) observed that the snow area in South America has decreased cyclically in the past 25 years using remote sensing technology. The period of snowmelt greatly influences the amount of water resources, climate change in surroundings, and downstream areas. Snow accumulation and ablation are diverse in different regions, and the estimation of snow-water equivalent can improve the accuracy of snow forecast (Kuraś et al., 2008; Dai et al., 2012). Therefore, the spatiotemporal distribution and variation of snow cover should be studied on a regional scale.

Precipitation and temperature are the main factors affecting the period of snow accumulation and ablation (Martinec and Rango, 1981; Waqas and Athar, 2019). Tachibana et al. (2007) made a preliminary estimation for Tokyo and nearby areas in Japan and discovered that snow cover did not significantly change with time. By analyzing the characteristics related to snow cover duration, Lethers and Luff (1997) observed that snow cover duration was highly correlated with precipitation and temperature. Schöner et al. (2019) reported that snow depth is mainly influenced by temperature at low altitudes and precipitation at high altitudes. They used snow-water equivalent data from 2002-2009 to interpret snow depth in northeast China by correlating snow cover with temperature and precipitation. The results showed that snow depth gradually decreased over time and temperature was the main influencing factor for snow cover change (Zhang, 2010). A study on the first and last days of snow cover over the past 42 years in the Greater Khingan Range indicated that the first day of snow cover was delayed, the last day was advanced, and the overall duration of snow cover was shorter (Chang, 2018). Snow cover is an important part of a climate system, and it serves as an indicator of climate change and overall climate. Accordingly, climate change also has an impact on the generation and maintenance of snow cover, and the changes in snow cover result from the combination of temperature, radiation, precipitation, altitude, and other climatic factors (Li et al., 2019; Orsolini et al., 2019). In this study, seasonal snow cover is classified into snow accumulation and snowmelt periods according to the variation and trend in the monthly snow depth over a 30-year period (Aizen et al., 1995). The main factors affecting snow cover duration are analyzed. The results lay a foundation to study the utilization of water resources based on snowmelt in the Mollisol areas of China under the prevalent climate change conditions, and provide data support for agricultural production and ecological environment monitoring. 


\section{Materials and methods}

\section{Study area}

Mollisol areas are mainly distributed in the northeast plain of China. Shown in Figure 1 , the study area is located between longitudes $119^{\circ} 01^{\prime}$ and $135^{\circ} 06^{\prime}$ and latitudes $30^{\circ} 48^{\prime}$ and $53^{\circ} 33^{\prime}$, and it covers $108.53 \times 10^{4} \mathrm{~km}^{2}$ (Wang et al., 2020). Due to the largescale cultivation in the Mollisol areas of northeast China, serious soil and water loss has occurred. Soil erosion in the study region has been detected in $27.5 \times 10^{4} \mathrm{~km}^{2}$, which represents approximately $27 \%$ of the total area. The study area has an average altitude of $446.811 \mathrm{~m}$, mean annual air temperature of $-5-11^{\circ} \mathrm{C}$, and annual precipitation of approximately $300-1000 \mathrm{~mm}$ varying from the west to east. Considering the regionalization based on water and soil conservation, there are six secondary regions within the Mollisol area according to dominant landforms: the Greater and Lesser Khingan Range, mountainous and hilly region in the southeast of the Greater Khingan Range, mountainous and hilly part of the northeast, Hulun Buir hilly plain, Songliao plain sandy soil, and Changbai and Wanda mountain hilly (MWR, 2012).

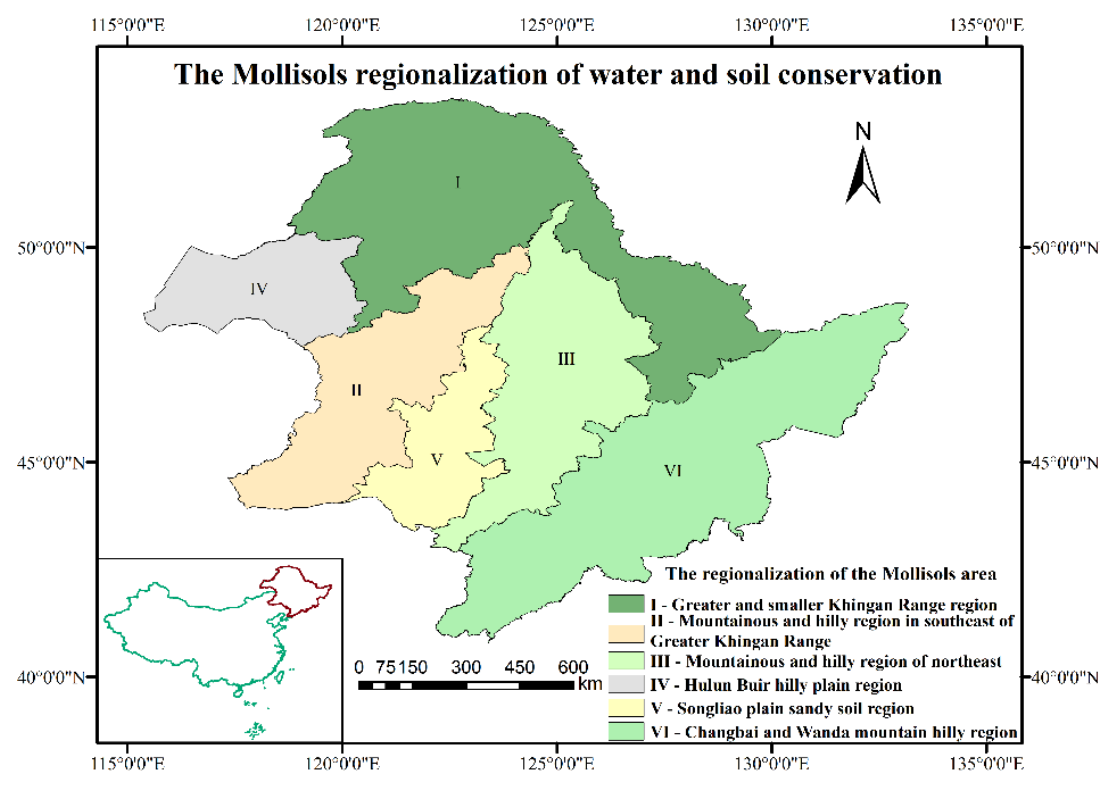

Figure 1. Study area

\section{Data}

A long-term series (1978-2016) of daily snow depth in China (http://westdc.westgis.ac.cn/) (Nie et al., 2019) was used for analyzing the snow cover (Dai and Che, 2014). Meteorological data was obtained from the national meteorological science center of China (http://data.cma.cn/). As shown in Table 1, the daily meteorological data was downloaded and collated from 71 meteorological stations, and it included precipitation, temperature, wind speed, and solar radiation from 1987 to 2016 . Quality control was performed to evaluate the homogeneity of the series. This control involved detection of any breaks caused by changes in the location or in the instruments of the stations. In addition, any questionable values were removed, such as daily precipitation amounts lower than zero, until the series showed continuity for several years and gaps lower than $<10 \%$ (Aguilar et al., 2005). 
Table 1. Information of the meteorological stations used in this study

\begin{tabular}{|c|c|c|c|c|c|c|c|c|c|}
\hline Code & Station & Lon./deg & Lat./deg & Altitude/m & Code & Station & Lon./deg & Lat./deg & Altitude/m \\
\hline 50136 & Mohe & 122.52 & 52.97 & 438.5 & 54157 & Siping & 124.38 & 43.12 & 179.5 \\
\hline 50246 & Tahe & 124.72 & 52.35 & 361.9 & 54161 & Changchun & 125.22 & 43.90 & 236.8 \\
\hline 50349 & Xinlin & 124.40 & 51.67 & 501.5 & 54181 & Jiaohe & 127.33 & 43.70 & 295.0 \\
\hline 50353 & Huma & 126.63 & 51.73 & 173.9 & 54186 & Dunhua & 128.20 & 43.37 & 524.9 \\
\hline 50442 & Jiagedaqi & 124.12 & 50.40 & 371.7 & 54195 & Wangqing & 129.78 & 43.30 & 244.8 \\
\hline 50468 & Aihui & 127.47 & 50.25 & 166.4 & 54273 & Huadian & 126.75 & 42.98 & 263.3 \\
\hline 50557 & Nenjiang & 125.23 & 49.17 & 242.2 & 54276 & Jingyu & 126.80 & 42.40 & 570.0 \\
\hline 50564 & Sunwu & 127.35 & 49.43 & 234.5 & 54284 & Donggang & 127.50 & 42.15 & 774.2 \\
\hline 50656 & Beian & 126.50 & 48.25 & 278.4 & 54285 & Erdao & 128.12 & 42.40 & 731.7 \\
\hline 50658 & Keshan & 125.88 & 48.05 & 236.0 & 54292 & Yanji & 129.50 & 42.87 & 257.3 \\
\hline 50742 & Fuyu & 124.48 & 47.80 & 162.7 & 54363 & Tonghua & 125.90 & 41.68 & 402.9 \\
\hline 50745 & Qiqihaer & 123.92 & 47.38 & 147.1 & 54374 & Linjiang & 126.88 & 41.80 & 379.7 \\
\hline 50756 & Hailun & 126.87 & 47.45 & 247.4 & 54377 & Jian & 126.22 & 41.15 & 225.1 \\
\hline 50774 & Yichun & 128.83 & 47.70 & 264.8 & 54386 & Changbai & 128.18 & 41.42 & 775.0 \\
\hline 50788 & Fuyin & 131.98 & 47.23 & 66.4 & 54254 & Kaiyuan & 124.05 & 42.53 & 98.2 \\
\hline 50844 & Tailai & 123.45 & 46.40 & 138.8 & 54259 & Qingyuan & 124.87 & 42.07 & 224.0 \\
\hline 50853 & Beilin & 126.97 & 46.62 & 179.6 & 54346 & Benxi & 123.78 & 41.30 & 185.4 \\
\hline 50854 & Anda & 125.32 & 46.38 & 149.3 & 54351 & Fushun & 124.07 & 41.92 & 118.5 \\
\hline 50862 & Tieli & 127.98 & 46.98 & 206.0 & 54486 & Xiuyan & 123.28 & 40.33 & 97.7 \\
\hline 50873 & Boli & 130.30 & 46.78 & 82.0 & 54493 & Kuandian & 124.78 & 40.72 & 260.1 \\
\hline 50877 & Yilan & 129.58 & 46.30 & 100.1 & 54497 & Dandong & 124.33 & 40.03 & 13.8 \\
\hline 50888 & Baoqing & 132.17 & 46.38 & 79.6 & 50425 & Flow Down & 120.18 & 50.25 & 581.4 \\
\hline 50950 & Zhaozhou & 125.25 & 45.70 & 148.7 & 50434 & Tulihe & 121.68 & 50.48 & 732.6 \\
\hline 50953 & Haerbin & 126.57 & 45.93 & 118.3 & 50514 & Manchuria & 117.32 & 49.58 & 661.8 \\
\hline 50963 & Tonghe & 128.73 & 45.97 & 108.6 & 50527 & Hailar & 119.70 & 49.25 & 649.6 \\
\hline 50968 & Shangzhi & 127.97 & 45.22 & 189.7 & 50548 & Xiaoergou & 123.72 & 49.20 & 286.1 \\
\hline 50978 & Jixi & 130.92 & 45.30 & 272.5 & 50603 & Xin Barag right Banner & 116.82 & 48.68 & 542.4 \\
\hline 50983 & Hulin & 132.97 & 45.77 & 100.2 & 50618 & Xin Barag left Banner & 118.27 & 48.22 & 642.0 \\
\hline 54094 & Mudanjiang & 129.67 & 44.50 & 305.7 & 50639 & Zhalantun & 122.73 & 48.00 & 306.5 \\
\hline 54096 & Suifenhe & 131.17 & 44.38 & 567.8 & 50727 & Arshaan & 119.93 & 47.17 & 997.2 \\
\hline 50936 & baicheng & 122.83 & 45.63 & 155.3 & 50834 & Suolun & 121.22 & 46.60 & 499.7 \\
\hline 50948 & Qianan & 124.02 & 45.00 & 146.3 & 54026 & Jarud Banner & 120.90 & 44.57 & 265.0 \\
\hline 50949 & Qianguo & 124.87 & 45.08 & 136.2 & 54027 & Bairin Left Banner & 119.40 & 43.98 & 486.2 \\
\hline 54041 & Tongyu & 123.07 & 44.80 & 150.0 & 54115 & Linxi & 118.03 & 43.63 & 825.0 \\
\hline 54049 & Changling & 123.97 & 44.25 & 188.9 & 54134 & Kailu & 121.28 & 43.60 & 241.0 \\
\hline 54063 & Fuyu & 126.00 & 44.97 & 196.8 & 54135 & Tongliao & 122.27 & 43.60 & 178.7 \\
\hline 54142 & Shuangliao & 123.53 & 43.50 & 114.9 & & & & & \\
\hline
\end{tabular}

\section{Average monthly snow depth (AMSD)}

The average monthly snow depth (AMSD) was calculated as the ratio of monthly accumulated snow depth to the number of snow cover days. AMSD values from October of each year to May of the subsequent year were calculated (Baronetti et al., 2019). The average monthly variation rate (AMVR) was analyzed. The linear change 
tendency of each climate factor was analyzed using the linear regression analysis method with one variable. A confidence level of $p<0.05$ was used to evaluate the significance of the trends (Shafiq et al., 2018; Yang et al., 2019). The linear regression equation is as follows:

$$
b=\frac{n \sum_{i=1}^{n} x_{i} y_{i}-\sum_{i=1}^{n} x_{i} \sum_{i=1}^{n} y_{i}}{n \sum_{i=1}^{n} x_{i}^{2}-\left(\sum_{i=1}^{n} x_{i}\right)^{2}}
$$

where $y_{i}=b \times x_{i}+a, a=\bar{y}-b \bar{x}, y_{i}$ is the AMSD data of the snow cover period of 1978-2016, $x_{i}$ is the time series, $a$ is the regression constant term, and $b$ is the regression coefficient. In this study, $b$ is used to quantitatively analyze the linear change tendency of climatic factors.

\section{Duration and first and last days of snow cover}

The first day of snow cover (SFD) is the $5^{\text {th }}$ day of the first spell of a 5-day consecutive snow fall in autumn or winter, and the end day snow cover (SED) is the last day of the last 5-day consecutive snow fall in the spring of the subsequent year. The snow cover duration (SCD) is defined as the sum of days with a snow depth of more than $1 \mathrm{~cm}$ (Gusain et al., 2016; Mo et al., 2017; Orozco et al., 2019).

\section{Snow cover duration and climate change}

The correlation between snow cover duration and temperature, precipitation, radiation, altitude, and latitude were analyzed for 1987-2016 according to the methods provided by Liu and Chen (2000) and Buisan et al. (2015).

\section{Periodic changes in snowmelt water volume}

Data on snowmelt water volume was obtained from the maximum depth in the snow accumulation period during 1987-2016. The average snow density was $0.298 \mathrm{~g} / \mathrm{cm}^{3}$ (Ma, 2017). The Morlet wavelet method was used to analyze the multitemporal and spatial scale variation of snowmelt water volume. The continuous wavelet transform was as follows:

$$
V_{\text {volum }}=\sum_{1}^{s} 0.298 \times \text { area } \times S D_{\max }
$$

where $V_{\text {volum }}$ is the volume of snowmelt water, area is a pixel area, and $S D_{\max }$ is the maximum snow depth.

$$
W_{f}(a, b)=\frac{1}{\sqrt{a}} \Delta t \sum_{k=1}^{N} f(k \Delta t) \bar{\psi}\left(\frac{t-b}{a}\right)
$$

where $W_{f}(a, b)$ can reflect the characteristics of time domain parameter $b$ and frequency domain parameter $a, \Delta t$ represents the sampling interval, and $f(k \Delta t)$ represents the output of the filter through the impulse response (Slavie et al., 2003). 


\section{Results and discussion}

\section{Temporal and spatial variation of snow depth}

Based on the seasonal changes in northeast China, the hydrological year (HY) was defined as the period from December 1 to September 30 of the next year. The snow cover period in the Mollisol region begins in early October and ends in early May. The spatiotemporal distribution of AMSD is shown in Figure 2. Snow accumulation was lower in October and November. Snowfall first appeared in Mohe and Tulihe of the Greater Khingan Range, where the AMSD was $0-5 \mathrm{~cm}$, and accumulation was rapid due to the influence of temperature. In February, the maximum value of AMSD was observed with an increasing trend from southwest to northeast. Owing to the influence of topography, AMSD in the Greater Khingan Range was 15-30 cm, and in the Changbai and Wanda mountain region it was $10-15 \mathrm{~cm}$. However, the values were lower in the plain and low-altitude regions. From mid-March, snow depth began to decrease and the snow completely melted in early May. The AMSD value of the Mollisol region became below the effective snow depth within May and October.
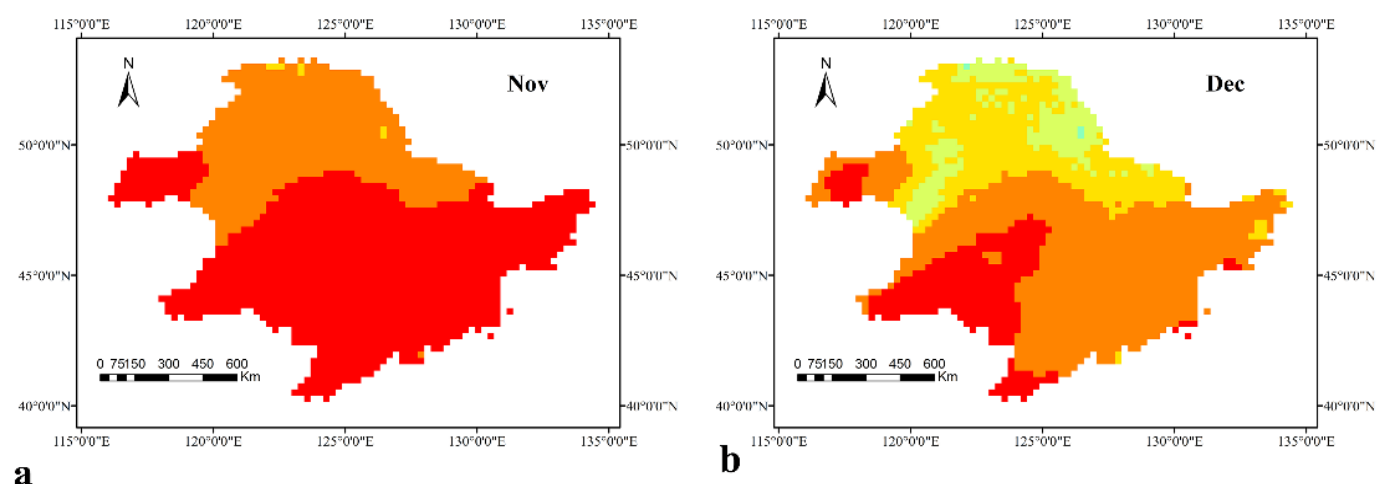

a
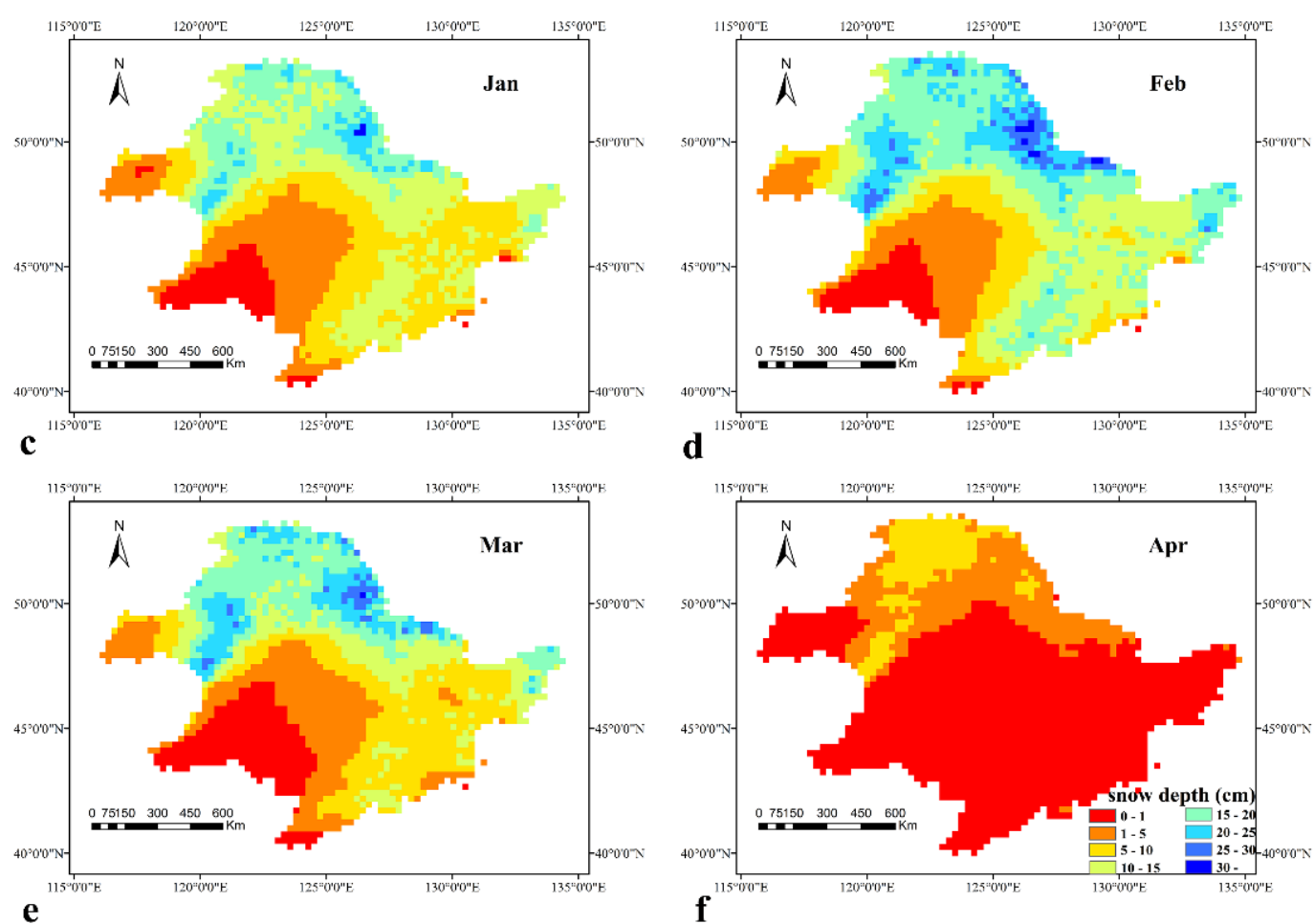

Figure 2. Average monthly snow depth (AMSD) in the study area 
The AMVR values for the 30-year period considered in the study are shown in Figure 3, which was calculated by Equation 1. The AMVR in the Mollisol region increased by $0-0.1 \mathrm{~cm} /$ year in November with no significant variation throughout the area. Large areas with significant increase of above $0.2 \mathrm{~cm} /$ year occurred in the mountainous and hilly regions of northeast China in December. In January, the AMVR shows an insignificant increasing trend in snow depth for most areas, particularly in the mountainous and hilly region of northeast at $0-0.1 \mathrm{~cm} /$ year. In February and March, an insignificant decrease is evidenced in large areas of the Greater and Lesser Khingan Range, while a significant increase occurs in the mountainous and hilly region of northeast and the Sanjiang plain, with variations higher than $0.2 \mathrm{~cm} /$ year. In April, increasing and decreasing trends each occupied approximately half of the study area, in which the southern part of the Songliao plain's sandy soil region presented a significant decreasing trend.

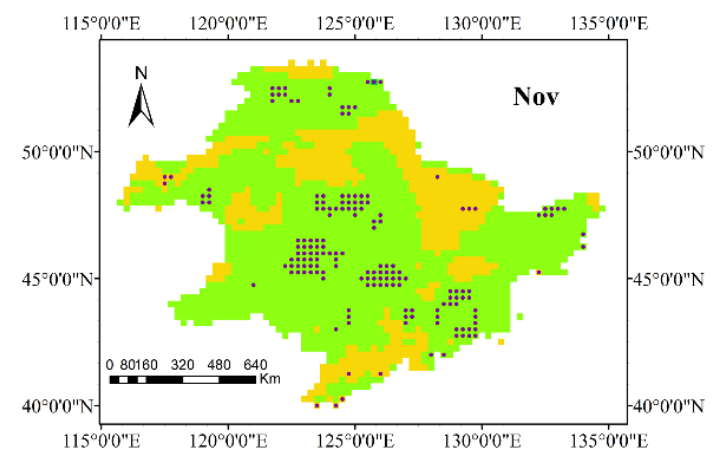

a
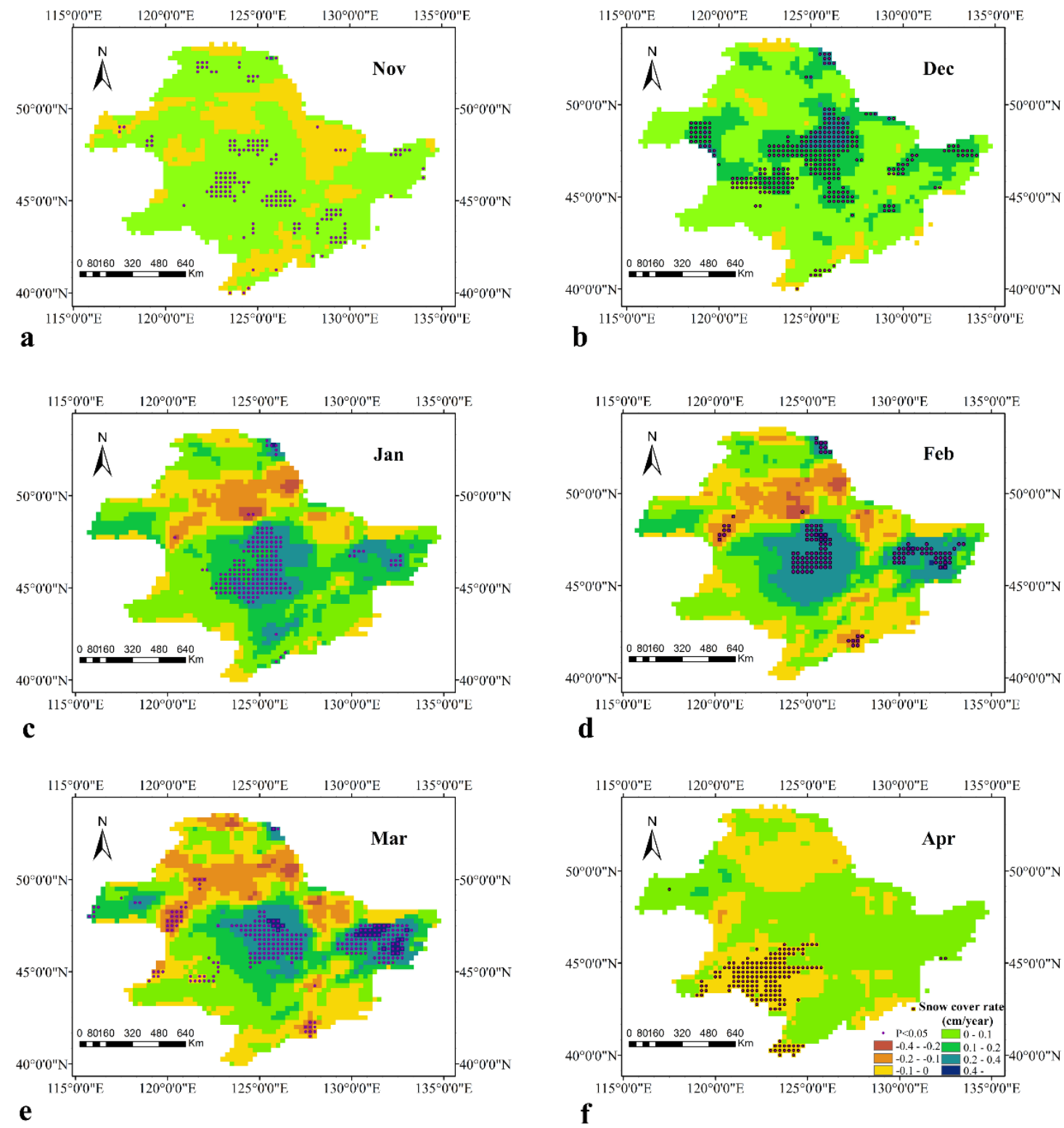

Figure 3. Average monthly variation rate (AMVR) of snow depth in the study area 


\section{Temporal and spatial variation of snow cover days}

The variations of monthly average and maximum snow depths in the Mollisol region shown in Figure 4 were consistent. The snow depth was shallow from October to November with a low rate of increase. From October to February, the snow depth increased at a fast rate and reached its maximum in February. Therefore, this period was defined as the snow accumulation period. From March to May, the depth of snow decreased continuously with a short duration of snowmelt. This period was defined as the snow ablation period.

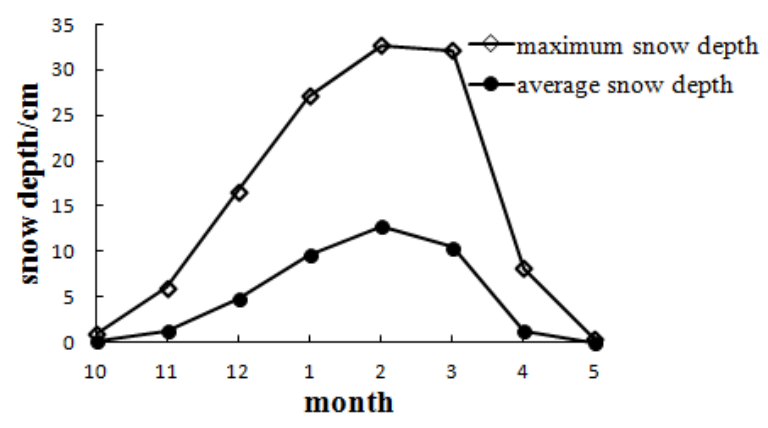

Figure 4. 30-year variation in monthly snow depth

As shown in Figure 5a, during the 30-year period, the first day of snow appeared in the Greater Khingan Range of the Mollisol region from the 12th to 30th day, followed by the Lesser Khingan Range region from the 30th to 60th day. The first day of snow in the Changbai and Wanda mountain hilly region and mountainous and hilly region of northeast occurred between the 60th and 90th day. In the Songliao plain sandy soil region and mountainous and hilly region in the southeast of the Greater Khingan Range, the first day of snow occurred between the 60th and 90th day. It was delayed from north to south, and there was no snow in the south of the hilly region. The first day of snow in the Hulun Buir hilly plain region occurred between the 90th and 150th day. Figure 5b shows that the last day of snow was delayed the most in the Greater and Lesser Khingan Range, where it occurred between the 200th and 220th day. For the Changbai and Wanda mountain hilly region, mountainous and hilly region of northeast, and Hulun Buir hilly plain region, it occurred between the 180th and 200th day. The last day of snow for the Songliao plain sandy soil region and hilly region in the southeast of Greater Khingan Range occurred progressively from north to south.

As shown in Figure 5c, the snow cover plural for the northern part of the Greater Khingan Range, lesser Khingan Range and Changbai and Wanda mountain hilly region, and Hulun Buir hilly plain region were 180-200, 150-180, and 120-150 days, respectively. The snow cover duration in the mountainous and hilly region southeast of the Greater Khingan Range, Songliao plain sandy soil region, and mountainous and hilly region of northeast advanced from north to south (Whetton et al., 1996). The annual average of maximum snow depth in the Greater and Lesser Khingan Range, north region, Changbai and Wanda mountain hilly region, and mountainous and hilly region of northeast were $20-30,>30,10-20$, and 5-10 cm, respectively. In addition, the annual average of maximum snow depth in the Songliao plain sandy soil region and mountainous and hilly region southeast of the Greater Khingan Range decreased from north to south. 


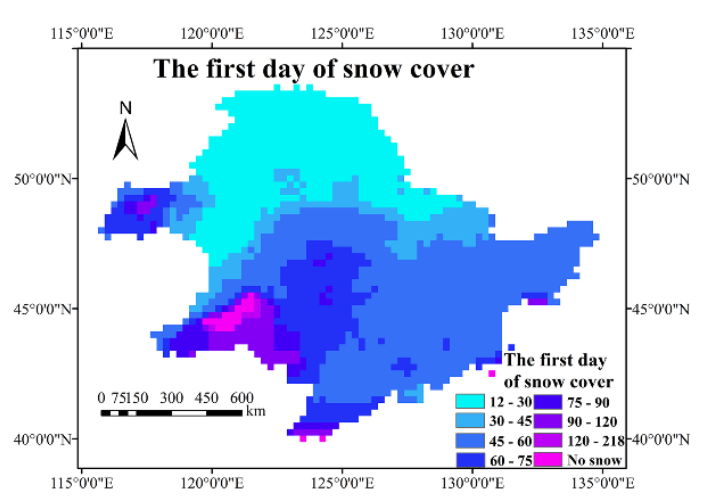

$\mathbf{a}$
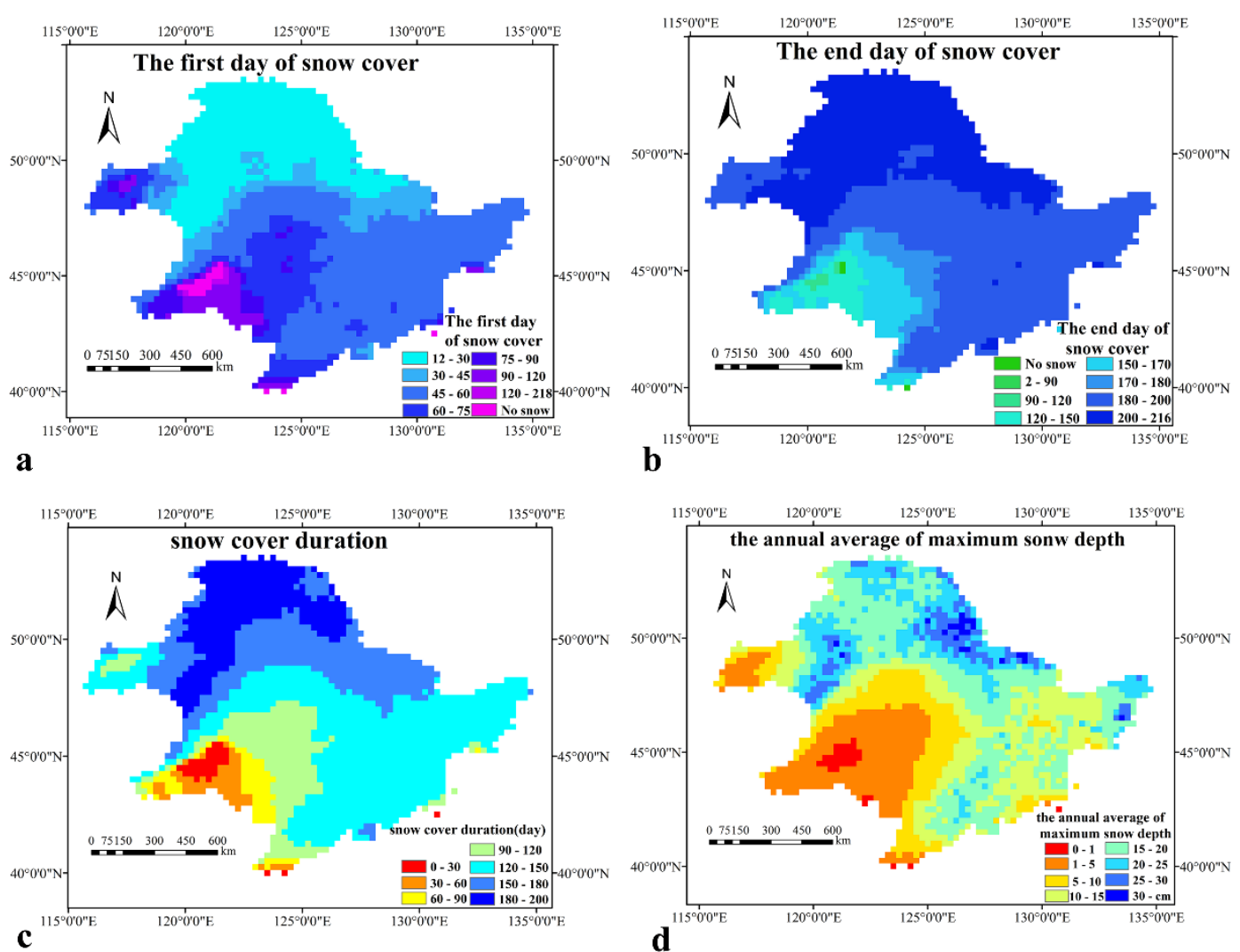

b

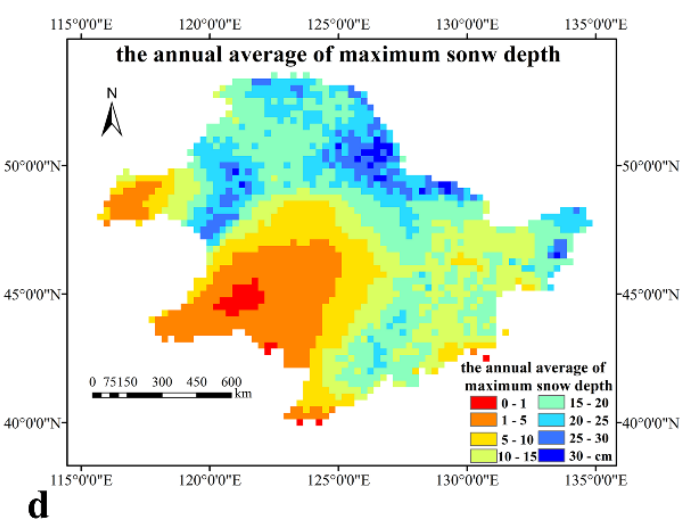

Figure 5. Snow cover in the study area during the study period: (a) first day of snow cover, (b) last day of snow cover, (c) duration of snow cover, and (d) annual average snow depth

\section{Snow cover days and climate change}

Linear regression analyses were performed to correlate average temperature, total precipitation, and latitude and altitude of meteorological stations with snow cover days and accumulation period, and the results are presented in Figure 6. Temperature presented a negative correlation with snow cover days during the snow accumulation period (Fig. 6a). No significant correlation was observed between total precipitation and snow cover days (Fig. 6b). The latitude (Fig. 6c) and altitude (Fig. 6d) of the meteorological stations were positively correlated with snow cover days during the accumulation period. Temperature was considered the main influencing factor for snow cover days during the accumulation period because its correlation value was the highest, at $\mathrm{R}^{2}=0.55$. The correlation between environmental factors and number of snow cover days during the snow accumulation period were, in order of significance: average temperature $>$ latitude of meteorological station $>$ altitude of meteorological station $>$ total precipitation.

Linear regression analyses were also performed to correlate average radiation, average temperature, and latitude and altitude of meteorological stations with snow cover days for the snow melt (ablation) period, and the results are presented in Figure 7. In the Mollisol region of northeast China, there was no correlation between total precipitation and snow cover days during the snow ablation period. However, there was a negative correlation between average temperature (Fig. $7 a$ ) and average radiation (Fig. 7b) with snow cover days. Altitude (Fig. 7c) and latitude (Fig. 7d) of 
meteorological stations were positively correlated with snow cover days. The correlation with temperature during the snow ablation period was the highest, at $\mathrm{R}^{2}=0.66$, which indicates that temperature presents the most influence on the number of snow cover days during the snow ablation period. The correlation with environmental factors were, in order of significance: average temperature > latitude of meteorological station $>$ average solar radiation $>$ altitude of meteorological station.
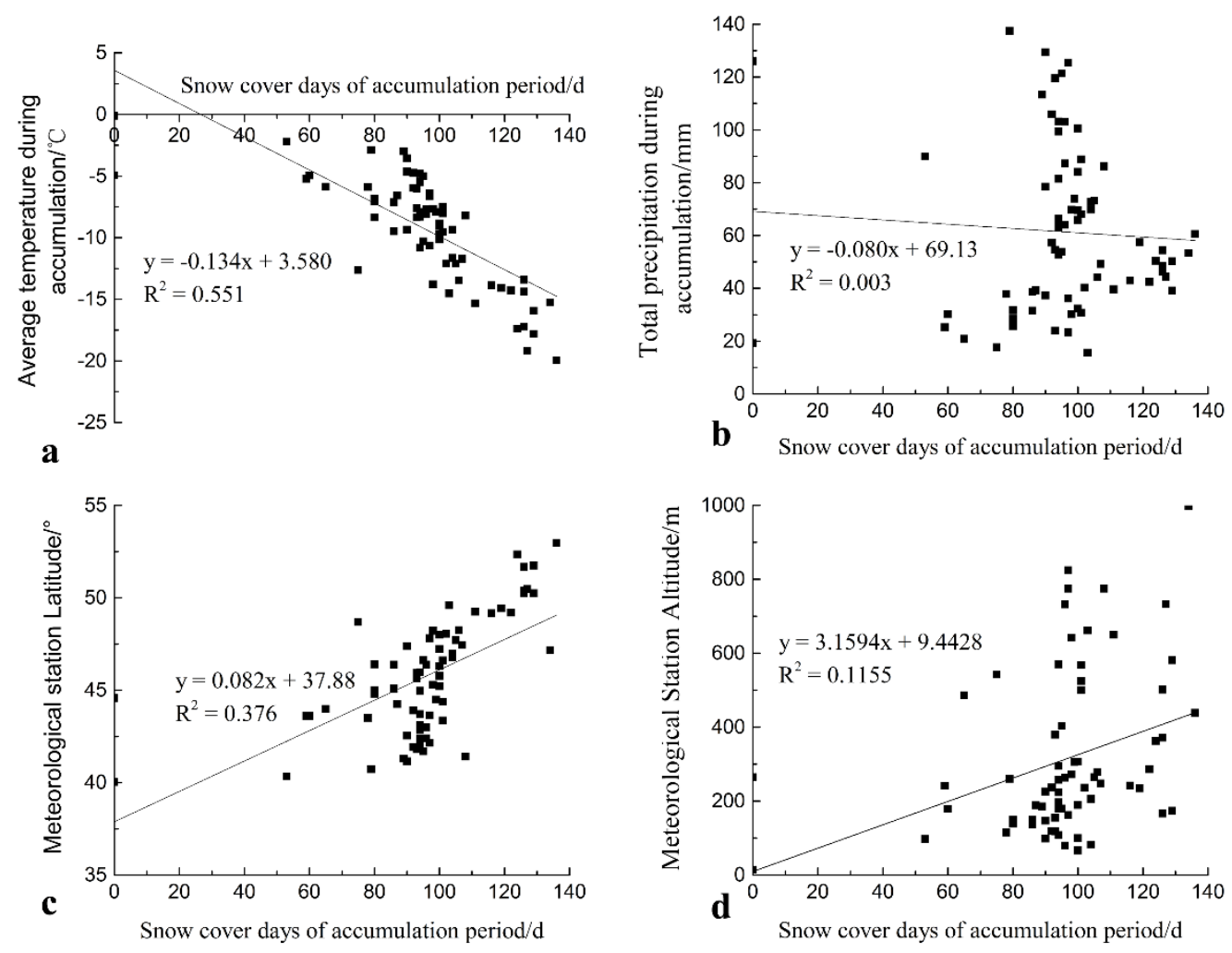

Figure 6. Correlation between snow cover days and climatic factors in the snow accumulation period: (a) average temperature, (b) total precipitation, (c) latitude of meteorological station, and $(d)$ altitude of meteorological station

\section{Time scale of snowmelt water volume}

Figure $8 a$ shows the volume diagram of the snowmelt water in the Mollisol region of northeast China, which is calculated by Equation 2. The annual volume of snowmelt water did not experience a continual increase or decrease, and the volume of snowmelt water varied by $2.764 \times 10^{9} \mathrm{~m}^{3}$ every ten years. In the northeast China, the long-term variability of snow cover is marked by a stochastic oscillation superimposed on a small increasing trend over the past 30 years. No abrupt change was found in snow cover. In addition, the minimum and maximum snowmelt water volume occurred at $35.089 \times 10^{9}$ and $97.646 \times 10^{9} \mathrm{~m}^{3}$ in 2008 and 2013, respectively. Figure $8 b$ shows the wavelet analysis diagram of the snowmelt water volume in the studied region, which is calculated by Equation 3, and it indicates that the variation period was the most obvious in 3-5 years. Before 2005, the annual variation period of snowmelt water volume in 10 years was obvious. After 2005, snowmelt water volume showed a variation period of 5-7 years, and this period gradually decreased. 


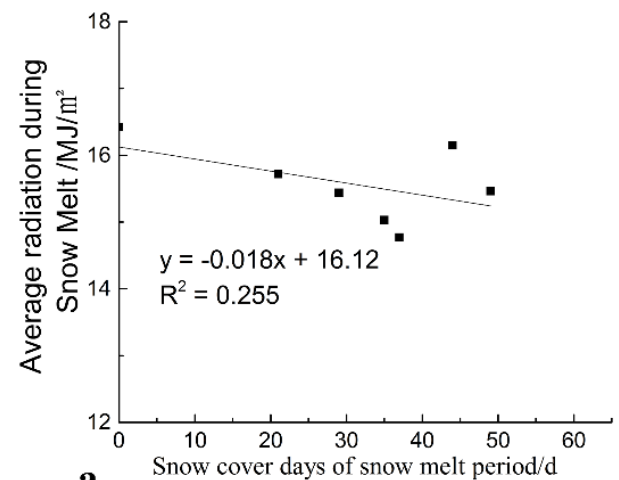

a

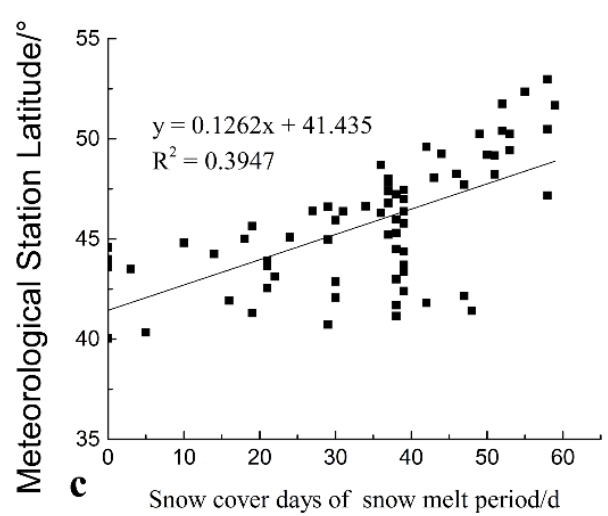

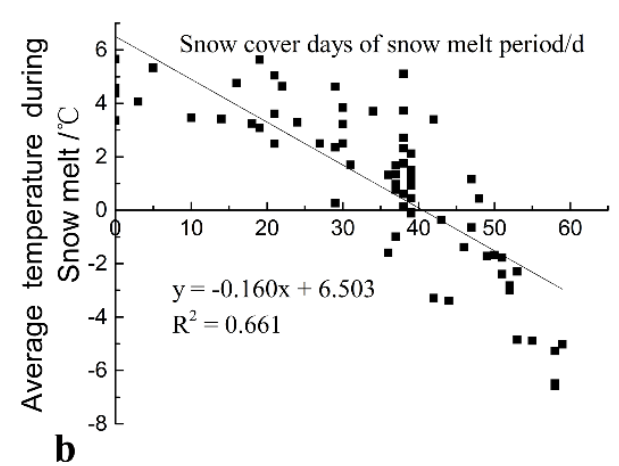

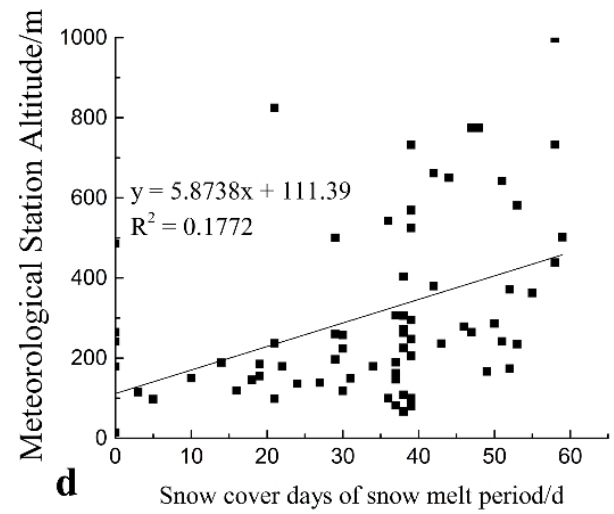

Figure 7. Correlation between snow cover days and climatic factors in the snow melt period: (a) average radiation, (b) average temperature, (c) latitude of meteorological station, and (d) altitude of meteorological station

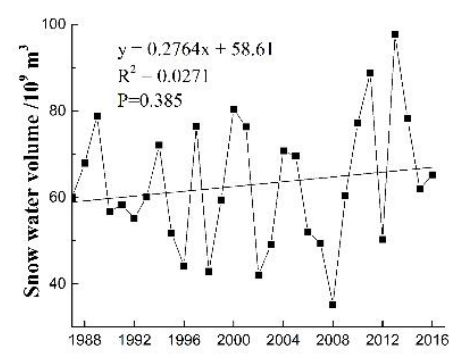

a

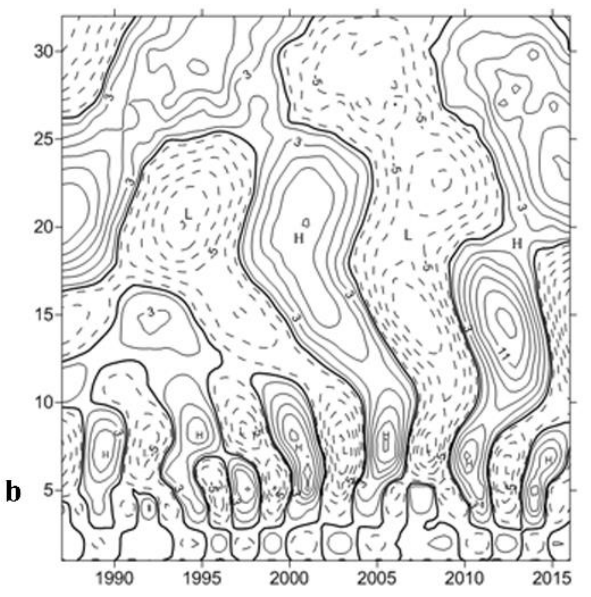

Figure 8. Morlet wavelet analysis of snowmelt water volume

Trujillo and Molotch (2014) report that the snow-water equivalent curve can represent hydrological indexes in a HY (Egli and Jonas, 2009; De Gregorio et al., 2019; Yang et al., 2019). Accordingly, the snow accumulation and ablation periods varied in different regions. In this study, the spatiotemporal distribution showed that snow cover began to accumulate in mid-November, reached the maximum depth by the end of 
February of the subsequent year, and completely melted in late March. The distribution pattern was consistent in terms of average maximum snow depth and number of snow cover days, and had the strong spatial heterogeneity in the whole area.

The results of this study contradict the trend of decreasing maximum snow cover in the Northern Hemisphere (Mote, 2003). The volume of snowmelt water in the Mollisol region of northeast China had no significant increase during the 30-year period. In terms of average snow depth under the global warming scenario, the Greater and Lesser Khingan Range and the Changbai and Wanda mountain hilly region showed a decrease, and the plain region showed an increase. The decrease in average snow depth at high attitudes is similar to those of previous studies conducted in the Alps and the Tianshan mountains (Li et al., 2019; Schöner et al., 2019). Meteorological data are mainly used to study the changes of snow depth, and the variation rate of snow depth is consistent with station observations (Tan et al., 2019). The results showed that the spatial variation of snow depth had no significant change.

Studies have shown that there is a strong correlation between spring temperatures and streamflow (Barnett et al., 2005; Niedzielski et al., 2019; Yang et al., 2020). Temperature and precipitation influence the duration of snow accumulation and ablation periods in high altitude mountains (Hantel et al., 2000). These studies reveal that average temperature and total precipitation can affect the entire snow season (Qin et al., 2006). However, in the present study, the results show that temperature was the main factor influencing snow accumulation and ablation periods. The difference may be due to the inconsistent length of time series, and the discrepancy in the selected sites and analytical methods. The findings also revealed that there was no correlation between precipitation and snow cover duration.

\section{Conclusion}

In the present study, the spatiotemporal distribution characteristics of snow cover during a 30-year period in the Mollisol region of northeast China were analyzed. Their correlation with climatic factors were also investigated. Data on the maximum snow cover depth was used to analyze the variation period of snowmelt water volume in the region. The main conclusions are as follows.

(1) The spatial distribution of snow depth was consistent with the secondary regionalization of the Mollisol region, and the maximum average monthly snow occurred in the Greater Khingan Range. Snow depth was largely affected by topographic factors, and it was relatively shallow in the plain region. The snow depth gradually increased from southwest to northeast, and the AMSD showed an increasing trend in most parts of the study region. However, the south region of the Greater and Lesser Khingan Range and the Changbai and Wanda mountain hilly region showed a decreasing trend of $0-0.4 \mathrm{~cm} / y e a r$. In contrast, the plain region showed an increasing trend of $0-0.4 \mathrm{~cm} /$ year.

(2) According to the variation pattern of monthly snow depth in the Mollisol region, the AMSD reached its maximum value in February. Therefore, the snow cover duration was divided into snow accumulation and ablation periods. Regarding correlation with snow cover days, temperature presented the highest positive value. The latitude and altitude of the meteorological stations also presented positive correlations with the number of snow cover days. In contrast, precipitation presented a non-significant correlation, and solar radiation presented a negative correlation. 
(3) The first snow cover day appeared in the northern area of the Greater Khingan Range, and the duration of the snow cover was long. The onset of the first snow cover day occurred last in the mountainous and hilly region in the southeast of the Greater Khingan Range, where the duration of snow cover was short. The duration of snow cover and distribution of snow depth consistently increased from southwest to northeast within the study area.

(4) The amount of snowmelt water in the Mollisol region showed an overall increasing trend, and the 3-5-year variation period was the most significant, while the 5-10-year variation period was not significant, and the cycle gradually decreased. Additionally, the accurate start time of the snow ablation remains to be further studied in the follw-up study.

Acknowledgements. This work has been funded by National Key R\&D Program of China (2016YFE022900).

Conflict of interests. The authors declare no conflict of interests.

\section{REFERENCES}

[1] Aguilar, E., Peterson, T. C., Obando, P. R., Frutos, R., Retana, J. A., Solera, M., Soley, J., García, I. G., Araujo, R. M. (2005): Changes in precipitation and temperature extremes in Central America and northern South America, 1961-2003. - Journal of Geophysical Research 110(D23).

[2] Aizen, V. B., Aizen, E. M., Melack, J. M. (1995): Climate, snow cover, glaciers, and runoff in the Tien Shan, Central Asia. - JAWRA Journal of the American Water Resources Association 31(6): 1113-1129.

[3] Barnett, T. P., Adam, J. C., Lettenmaier, D. P. (2005): Potential impacts of a warming climate on water availability in snow-dominated regions. - Nature 438(7066): 303-309.

[4] Baronetti, A., Fratianni, S., Acquaotta, F., Fortin, G. (2019): A quality control approach to better characterize the spatial distribution of snow depth over New Brunswick, Canada. - International Journal of Climatology 39(14): 5470-5485.

[5] Basang, D., Barthel, K., Olseth, J. (2017): Satellite and ground observations of snow cover in Tibet during 2001-2015. - Remote Sensing 9(11): 1201.

[6] Brown, R., Derksen, C., Wang, L. (2007): Assessment of spring snow cover duration variability over northern Canada from satellite datasets. - Remote Sensing of Environment 111(2-3): 367-381.

[7] Buisan, S. T., Saz, M. A., López-Moreno, J. I. (2015): Spatial and temporal variability of winter snow and precipitation days in the western and central Spanish Pyrenees. International Journal of Climatology 35(2): 259-274.

[8] Chang, A. T. C., Foster, J. L., Hall, D. K. (2017): Nimbus-7 SMMR derived global snow cover parameters. - Annals of Glaciology 9: 39-44.

[9] Chang, S. L. (2018): Study on the Temporal and Spatial dynamics of snow cover of Great Xing'an Mountains' forest region, Inner Mongolia. - Master Thesis, University of Inner Mongolia agricultural university, China.32-33.

[10] Qin, D. H., Liu, S. Y., Li, P. J. (2006): Snow cover distribution, variability, and response to climate change in western China. - Journal of Climate 19(9): 1820-1833.

[11] Dai, L., Che, T. (2014): Spatiotemporal variability in snow cover from 1987 to 2011 in northern China. - Journal of Applied Remote Sensing 8(1): 1-16,

[12] Dai, L., Che. T., Wang. J., Zhang. P. (2012): Snow depth and snow water equivalent estimation from AMSR-E data based on a priori snow characteristics in Xinjiang, China. - Remote Sensing of Environment 127: 14-29. 
[13] De Gregorio, L., Günther. D., Callegari, M., Strasser, U., Zebisch, M., Bruzzone, L., Notarnicola, C. (2019): Improving SWE estimation by fusion of snow models with topographic and remotely sensed data. - Remote Sensing 11(17): 2033.

[14] Egli, L., Jonas, T. (2009): Hysteretic dynamics of seasonal snow depth distribution in the Swiss Alps. - Geophysical Research Letters 36(2): 1-5.

[15] Fassnacht, S. R., Heun, C. M., López Moreno, J. I., Latron, J. (2013): Variability of snow density measurements in the Río Esera Valley, Pyrenees Mountains, Spain. - Cuadernos de Investigación Geográfica 36(1): 14.

[16] Fassnacht, S. R., Brown, K. S. J., Blumberg, E. J., López Moreno, J. I., Covino, T. P., Kappas, M., Huang, Y., Leone, V., Kashipazha, A. H. (2018): Distribution of snow depth variability. - Frontiers of Earth Science 12(4): 683-692.

[17] Foster, J. L., Chang, A. T. C., Hall, D. K. (1997): Comparison of snow mass estimates from a prototype passive microwave snow algorithm, a revised algorithm and a snow depth climatology. - Remote Sensing of Environment 62(2): 132-142.

[18] Gusain, H. S., Mishra, V. D., Arora, M. K., Mamgain, S., Singh, D. K. (2016): Operational algorithm for generation of snow depth maps from discrete data in Indian Western Himalaya. - Cold Regions Science and Technology 126: 22-29.

[19] Hantel, M., Ehrendorfer, M., Haslinger, A. (2000): Climate sensitivity of snow cover duration in Austria. - International Journal of Climatology 20(6): 615-640.

[20] Josberger, E. G., Mognard, N. M., Matthews, B., Lind, R., Carroll, T. (2017): Snowpack water-equivalent estimates from satellite and aircraft remote-sensing measurements of the Red River basin, north-central U.S.A. - Annals of Glaciology 26: 119-124.

[21] Kunkel, K. E., Robinson, D. A., Champion, S., Yin, X., Estilow, T., Frankson, R. M. (2016): Trends and extremes in northern hemisphere snow characteristics. - Current Climate Change Reports 2(2): 65-73.

[22] Kuraś, P. K., Weiler, M., Alila, Y. (2008): The spatiotemporal variability of runoff generation and groundwater dynamics in a snow-dominated catchment. - Journal of Hydrology 352(1-2): 50-66.

[23] Leathers, D. J., Luff, B. L. (1997): Characteristics of snow cover duration across the northeast United States of America. - International Journal of Climatology 17(14): 15351547.

[24] Li, G., Wang, Z. S., Huang, N. (2018): A snow distribution model based on snowfall and snow drifting simulations in mountain area. - Journal of Geophysical Research: Atmospheres. https://doi.org/10.1029/2018JD028434.

[25] Li, Q., Yang, T., Zhou, H., Li, L. (2019): Patterns in snow depth maximum and snow cover days during 1961-2015 period in the Tianshan Mountains, Central Asia. Atmospheric Research 228: 14-22.

[26] Liu, X., Chen, B. (2000): Climatic warming in the Tibetan Plateau during recent decades. - International Journal of Climatology 20(14): 1729-1742.

[27] Liu, Y., Li, L. H., Chen, X., Yang, J. M., Hao, J. S. (2018): Spatial distribution of snow depth based on geographically weighted regression kriging in the Bayanbulak Basin of the Tianshan Mountains, China. - Journal of Mountain Science 15(1): 33-45.

[28] López-Moreno, J. I., Fassnacht, S. R., Heath, J. T., Musselman, K. N., Revuelto, J., Latron, J., Morán-Tejeda, E., Jonas, T. (2013): Small scale spatial variability of snow density and depth over complex alpine terrain: implications for estimating snow water equivalent. - Advances in Water Resources 55: 40-52.

[29] Ma, S. W. (2017): Research on the characteristics of seasonal snow at low hill area in northeast China. - Master Thesis, Shenyang Agricultural University, China, pp. 18-19.

[30] Martinec, J., Rango, A. (1981): Areal distribution of snow water equivalent evaluated by snow cover monitoring. - Water Resources Research 17(5): 1480-1488.

[31] Mo, H. M., Hong, H. P., Fan, F. (2017): Using remote sensing information to estimate snow hazard and extreme snow load in China. - Natural Hazards 89(1): 1-17. 
[32] Mote, P. W. (2003): Trends in snow water equivalent in the Pacific Northwest and their climatic causes. - Geophysical Research Letters 30(12).

[33] Nie, Y., Wang, Y., Lv, X. (2019): Acquiring the arctic-scale spatial distribution of snow depth based on AMSR-E snow depth product. - Journal of Atmospheric and Oceanic Technology 36(10): 1957-1965.

[34] Niedzielski, T., Szymanowski, M., Miziński, B., Spallek, W., Witek-Kasprzak, M., Ślopek, J., Kasprzak, M., Błaś, M., Sobik, M., Jancewicz, K., Borowicz, D., Remisz, J., Modzel, P., Męcina, K., Leszczyński, L. (2019): Estimating snow water equivalent using unmanned aerial vehicles for determining snow-melt runoff. - Journal of Hydrology 578: 124046.

[35] Orozco, I., Francés, F., Mora, J. (2019): Parsimonious modeling of snow accumulation and snowmelt processes in high mountain basins. - Water 11(6): 1288.

[36] Orsolini, Y., Wegmann, M., Dutra, E., Liu, B., Balsamo, G., Yang, K., de Rosnay, P., Zhu, C., Wang, W., Senan, R., Arduini, G. (2019): Evaluation of snow depth and snow cover over the Tibetan Plateau in global reanalyses using in situ and satellite remote sensing observations. - The Cryosphere 13(8): 2221-2239.

[37] Schöner, W., Koch, R., Matulla, C., Marty, C., Tilg, A. M. (2019): Spatiotemporal patterns of snow depth within the Swiss-Austrian Alps for the past half century (1961 to 2012) and linkages to climate change. - International Journal of Climatology 39(3): 1589-1603.

[38] Scipión, D. E., Mott, R., Lehning, M., Schneebeli, M., Berne, A. (2013): Seasonal smallscale spatial variability in alpine snowfall and snow accumulation. - Water Resources Research 49(3): 1446-1457.

[39] Shafiq, M. u., Ahmed, P., Islam, Z. u., Joshi, P. K., Bhat, W. A. (2018): Snow cover area change and its relations with climatic variability in Kashmir Himalayas, India. - Geocarto International 34(6): 688-702.

[40] Slavie, J., Simonovski, I., Bolterzar, M. (2003): Damping identification using a continuous wavelet transform: application to real data. - Sound Vib 262: 291-307.

[41] Tachibana, Y., Nakamura, T., Tazou, N. (2007): Interannual variation in snowaccumulation events in Tokyo and its relationship to the Eurasian pattern. - SOLA 3: 129-132.

[42] Tan, X. J., Wu, Z. N., Mu, X. M., Gao, P., Zhao, G. J., Sun. W. Y., Gu, C. J. (2019): Spatiotemporal changes in snow cover over China during 1960-2013. - Atmospheric Research 218: 183-194.

[43] Tang, Y., Zhang, W., Liu, L., Li, G. (2019): Spring thaw classification based on AMSR-E brightness temperature in the central Tibetan Plateau. - International Journal of Remote Sensing 40(17): 6542-6552.

[44] The Ministry of Water Resources of the People's Republic of China (MWR) (2012): National Soil and Water Conservation Division (trial). - Ministry of Water Resources, Beijing (in Chinese).

[45] Trujillo, E., Molotch, N. P. (2014): Snowpack regimes of the Western United States. Water Resources Research 50(7): 5611-5623.

[46] Wang, B., Zhao, X., Wang, X., Zhang, Z., Yi, L., Hu, S. (2020): Spatial and temporal variability of soil erosion in the black soil region of Northeast China from 2000 to 2015. - Environmental Monitoring and Assessment 192(6). 370.

[47] Waqas, A., Athar, H. (2019): Spatiotemporal variability in daily observed precipitation and its relationship with snow cover of Hindukush, Karakoram and Himalaya region in northern Pakistan. - Atmospheric Research 228: 196-205.

[48] Whetton, P. H., Haylock, M. R., Galloway. R. (1996): Climate change and snow-cover duration in the Australian Alps. - Climatic Change 32(4): 447-479.

[49] Xu, J., Li, H., Liu, X., Hu, W., Yang, Q., Hao, Y., Zhen, H., Zhang, X. (2019): Gully erosion induced by snowmelt in Northeast China: a case study. - Sustainability 11(7): 2088. 
[50] Yang, T., Li, Q., Ahmad, S., Zhou, H., Li, L. (2019): Changes in snow phenology from 1979 to 2016 over the Tianshan Mountains, Central Asia. - Remote Sensing 11(5): 499.

[51] Yang, T., Li, Q., Liu, W., Liu, X., Li, L., De Maeyer, P. (2020): Spatiotemporal variability of snowfall and its concentration in northern Xinjiang, Northwest China. Theoretical and Applied Climatology 139: 1247-1259.

[52] Zhang, H. J. (2010): Study on spatio-temporal variations of snow from 2000 to 2009 in Northeast China. - Master Thesis, JiLin University, China.

[53] Zhang, T. (2005): Influence of the seasonal snow cover on the ground thermal regime: an overview. - Reviews of Geophysics 43(4). 